\title{
A Survey of the Relationship between the Use of Mobile Internet Times and the Healthy Lifestyle of College Students
}

\author{
Zhihui Zhu \\ School of Information and Mathematics, Yangtze University, Jingzhou 434023, China
}

\begin{abstract}
China fully access to the mobile Internet era. The Internet usage of college students in the mobile Internet era and its impact on healthy lifestyles are the urgent content for social and university workers to understand. In this paper, through the questionnaire survey, spss software correlation analysis, to understand the mobile Internet era of college students use the relationship between college students and healthy lifestyles.
\end{abstract}

Keywords : lifestyle network using mobile Internet college students

\section{Introduction}

In order to understand the relationship between the use of college students' network and the healthy living habits of college students, the questionnaire of college students' network usage and college students' EQ life is distributed. college students from Hunan, Hubei, Henan, Zhejiang and other provinces were investigated, 2400 questionnaires were issued, and 2148 questionnaires were valid. The correlation between Internet usage and healthy lifestyle of college students was analyzed by statistical software SPSS. Combined with case analysis, thematic design research, etc., comparative analysed the relationship between healthy lifestyle and network use, to understand the impact on healthy among different students' using network. Through the study and analysis of the relationship between the network and the healthy lifestyle of college students, to provide guidance for instructing students to use the network and cultivate healthy lifestyles.

\section{The relationship between the use of the network and the habit of exercise}

From the main use of the Internet point of view, respondents who mainly use the Internet for checking information and news exercise more healthily. (Correlation coefficient $0.149,0.157$ ). From the purpose of using the Internet, respondents who use the Internet for obtaining information and skills exercise more healthily. exercise and lifestyle health or not and other purposes of the Internet have no statistical correlation. (Correlation coefficient is $0.182,0.212$ ). From the way of communication with the users, respondents who interflow with net friends through the BBS, Email and raining gifts exercise more healthily. (Correlation coefficient is $0.175,0.125,0.146$ ). It is obvious that students who exercise healthily, in the Internet use is mainly used to check the information and read the news, the purpose of the Internet for the main access to information and knowledge and technology, in the way of communication with users mainly use BBS, Email, send Gift way of communication.

\section{The relationship between the use of the network and the habit of life}

From the main use of the Internet point of view, respondents who mainly use Internet for shopping living more unhealthy. (Correlation coefficient is -0.161). From the point of view of the exchange with the users, respondents who mainly use Email to communicate with net friends have more healthy habits. (Correlation coefficient is 0.175). From the Internet point of view, the living quarters of the respondents on the law of life is more unhealthy, with mobile Internet users surveyed more healthy life. (The correlation coefficient is $-0.14,0.184$ ) Internet trust friends more respondents, the law of life the more healthy lifestyle. (Correlation coefficient of 0.129 ) respondents who did not have the computer live a more healthy life. (The correlation coefficient of 0.187) It is obvious that students who live a healthy life,the main purpose of using Internet is not shopping, the Internet location is mainly used in mobile phones rather than in the dormitory, and users in the way of communication mainly use Email way, do not have a computer, Network trust more friends.

\section{The relationship between the use of the network and the habit of eating}

From the purpose of the Internet, the purpose of the Internet is to learn the knowledge and technology of the recipients of eating habits more healthy. (Correlation coefficient 0.121). Internet trust more friends the more respondents, the law of life the more healthy lifestyle. (Correlation coefficient of 0.141 ) visible diet nutrition behavior habit of healthy college students, the purpose of the Internet is to learn knowledge, network trust more friends. 


\section{The relationship between the use of the network and the habit of health hazards}

From the Internet point of view, in the school room Internet access to the health hazards of the respondents more unhealthy. (The correlation coefficient is -0.132) From the point of view of the communication with the users, the habit of health hazard is mainly health with the users through QQ communication, and the health habits of the respondents who communicate mainly through MSN are more unhealthy. (Correlation coefficient is $0.161,-0.154$ ). Health can be seen healthy habit of students, in the Internet site is not through the school room Internet, in the way of friends to choose QQ instead of MSN.

\section{The relationship between the use of the network and the habit of health responsibility}

From the main purpose of the Internet, the Internet is mainly used for chatting, check the information, listen to the music of the respondents health habits more healthy, the Internet is mainly used to play the game's health responsibility of the respondents are more unhealthy. (Correlation coefficient is $0.141,0.125,0.14$, -0.136). From the purpose of the Internet, the purpose of the Internet is to obtain information, and the distant family and friends to contact and learn the knowledge of the health of the respondents health habits more healthy. (Correlation coefficient is $0.186,0.141,0.19)$. From the choice of friends, health responsibility behavior and the choice of friends and the other's gender and knowledge of the ability. (The correlation coefficient is $0.136,-0.121$ ) From the point of view of the communication with the users, it is more healthy with the habit of the health responsibility of the respondents who communicate mainly by email. (Correlation coefficient is 0.152). From the Internet time point of view, the Internet time and health responsibility behavior is inversely proportional to the Internet time the shorter the respondents health responsibility behavior more healthy habits. (The correlation coefficient is -0.158) From the point of view of the Internet, the health responsibility of the respondents on the dormitory is more unhealthy, the health of the respondents in the school room, the mobile Internet is more healthy, healthy and healthy way of life and other There is no statistical relevance. (The correlation coefficient is $-0.24,0.167,0.232$ ) There is no person who owns the computer, health is more healthy. (Correlation coefficient of 0.185 ) visible health responsibility behavior habit of healthy college students, in the Internet use mainly for chat, check the information and listen to music rather than for the game, the purpose of the Internet is to get information, and distant family friends Contact and learn knowledge and technology, in the way of communication with friends mainly use Email way exchange, the Internet location in the school room, mobile phone rather than dormitory, the Internet time is short, do not have their own computer, with the choice of friends of gender and knowledge ability Certain relationship.

\section{Reference}

[1] How much the impact of the network on young people in the end [N]. 2002-5-19 $(1,2)$. China Education News.

[2] Wang, Li Jiang, zhongli. 2003 (5): 87-88. An Investigation and Reflection on the Network Life of College Students [J]. Liaoning Education Research. 